\title{
Isolation and Bioactivity Screening of Endophytic Fungi from Commelina diffusa
}

\author{
Mahmuda Nasrin ${ }^{1,2}$, Farhana Afroz ${ }^{2}$, Mst. Nadira Begum ${ }^{3}$, Satyajit Roy Rony², Suriya Sharmin², \\ Fatema Moni², Md. Sohel Rana', Md. Hossain Sohrab ${ }^{2, *}$
}

1'Department of Pharmacy, Jahangirnagar University, Savar, Dhaka, BANGLADESH.

2Pharmaceutical Sciences Research Division, BCSIR Laboratories-Dhaka, Bangladesh Council of Scientific and Industrial Research (BCSIR), Dhaka, BANGLADESH.

${ }^{3}$ Biological Research Division, BCSIR Laboratories-Dhaka, Bangladesh Council of Scientific and Industrial Research (BCSIR), Dhaka, BANGLADESH.

\begin{abstract}
Background: Endophytic fungi are able to produce many secondary metabolites and thus their availability and biological activity created new horizons for different pharmaceutical and agricultural approaches. Objective: For the ethnobotanical antiquity of Commelina diffusa in Bangladesh, this study is aimed at evaluating the endophytic fungal collection of Commelina diffusa and their bioactive potential. Methods: Endophytic fungi were isolated by the surface sterilization technique and identified using the microscopic procedure. Isolated fungal strains were solvent extracted. Disc diffusion method, DPPH free radical scavenging assay, brine shrimp lethality bioassay had been used for the determination of antibacterial, antioxidant, cytotoxic activities respectively. Results: Eight fungal strains were isolated and six of them were identified up to the genus level as Fusarium sp. (CDLE 1, CDRE 1, CDRE 2, CDRE 3, CDBE 1) and Alternaria sp. (CDBE 3 ) according to morphological and microscopical characters. Three of the eight isolated endophytes i.e., CDBE 2, CDRE 1 and CDRE 2 showed potential activity against $A$. niger in comparison with ketoconazole ( $30 \mu \mathrm{g} / \mathrm{disc})$. Ethyl acetate extract CDBE 3 fungal extract demonstrated significant antioxidant and cytotoxic activities. Conclusion: The present study has proven that Commelina diffusa may be a rich source of medicinally important endophytic fungi and our findings may form a basis for further studies on endophytic fungi from medicinal plants for use in medicine, industry and agriculture.

Key words: Endophytic fungi, Fusarium sp., Alternaria sp., Antibacterial, Antioxidant, Cytotoxic activity.
\end{abstract}

\section{INTRODUCTION}

Endophytes are micro-organisms (bacteria or fungi) that migrate to healthy plant tissue intercellularly and intracellularly without causing any noticeable symptoms of illness to the host species. ${ }^{1}$ Until now they are ubiquitous, colonizing in all plants and produce no harm to the host plants. Endophytes isolated from medicinal plants showed bioactivity for broad spectrum of pathogenic micro-organisms to control microbial pathogens. Hundreds of natural products including alkaloids, terpenoids, flavonoids and steroids have already been isolated from endophytes. ${ }^{2}$ Endophytes are capable of synthesizing bioactive secondary metabolites that are known to have antibiotics, immunosuppressant's, anticancer agents, biological control agents and other functionality. This potentially could result in improved host growth and the diverse ecological niches of these organisms may be helpful in agriculture. So far, more than ten thousand endophytic strains had already been isolated and characterized, including bacterium, fungus and actinomycete from the medicinal plants. As a part of our continuous screening for antimicrobial fungi from plant, Commelina diffusa Burm. F. has been investigated in this study. ${ }^{3}$ Commelina diffusa Burm. F. (Day flower, Bengali name:
Submission Date: 21-07-2020; Revision Date: 15-12-2021; Accepted Date: 12-04-2021

DOI: 10.5530/ijper.55.3.156 Correspondence:

Dr. Md. Hossain Sohrab Chief Scientific Officer and Scientist-in-Charge,

Pharmaceutical Sciences Research Division, BCSIR Laboratories Dhaka, Bangladesh Council of Scientific and Industrial research (BCSIR), Dr. Qudrat-I-Khuda Road, Dhanmondi, Dhaka-1205, BANGLADESH Phone: $+880-1720121525$ Email id: mhsohrab@bcsir. gov.bd

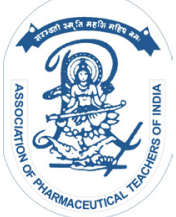

www.ijper.org 
manaina), a medicinal herb is used to treat various diseases traditionally. Biological activity evaluation revealed its potential in anti-inflammatory, ${ }^{4}$ antioxidant, ${ }^{3,4}$ antibacterial, ${ }^{3,5}$ anti-fungal, ${ }^{5}$ nephroprotective, ${ }^{6}$ hepatoprotective, ${ }^{6} \mathrm{CNS}$ depressant ${ }^{7}$ activities of this plant. The main objective of the present study was to isolate and characterize the endophytic fungi of $C$. diffusa available in Bangladesh and evaluation of their antibacterial, antioxidant and cytotoxicity activities.

\section{MATERIALS AND METHODS}

\section{Collection and identification of plant material}

Fresh and healthy (no visual infection) parts of the plant (leaves, bark and root) of Commelina diffusa were collected from Gazipur district, Bangladesh in June, 2017. The plants was identified a voucher specimen (ACC. No. 38390) and authenticated at the Bangladesh National Herbarium, Dhaka, Bangladesh. All the part (cutting length $=1 \mathrm{~cm}$ ) of the plant were processed within 6 hr of collection and screened for the occurrence of endophytic fungi.

\section{Surface sterilization and isolation of endophytic fungi}

At first plant materials were washed several times under running tap water, followed by washing in distilled water. Surface sterilization was then done by the suitably modified method of Petrini et al. $1986 .{ }^{8}$ The plant materials were further cut aseptically at their perimeters to reveal the interior surface to the water agar media when sterilization process completed. For each plant part, three segments were placed in petri dishes containing water agar media adjusted with streptomycin at $200 \mathrm{mg} / \mathrm{L}$ concentration. The dishes were closed with parafilm and incubated at $28^{\circ} \mathrm{C}$. After incubation period, the visual growth of fungus was observed from the plating date and isolated fungal tips were transferred to fresh potato dextrose agar (PDA) media without the addition of antibiotics to obtain pure fungal cultures. Nonsterilized culture used as negative control. The purified endophytic isolates were then transferred separately to PDA slants and stored at $4^{\circ} \mathrm{C}$ for further use.

\section{Chemical screening}

Chemical screening was performed on the fungal extracts of $C$. diffusa by thin layer chromatography (TLC) method as described by Wagner and Bladt, 1996 to ascertain the presence groups of starch, tannins, glycosides, terpenoids, flavonoids, steroids, alkaloids and so on. ${ }^{9}$ The presence of chemical compound in the extracts were detected using TLC method with mobile phase of Toluene $/ 10 \%$ EtOAc under UV light at $254 \mathrm{~nm}, 365 \mathrm{~nm}$ and by spraying with $1 \%$ vanillin in concentrated $\mathrm{H}_{2} \mathrm{SO}_{4}$ solution followed by heating at $105^{\circ} \mathrm{C}$, respectively. ${ }^{20,11}$

\section{Macroscopic and microscopic identification}

Morphological characterization was done on PDA following standard manuals ${ }^{12,13}$ and observing different morphological patterns such as growth rate, hyphae, color of the colony and medium, surface texture, margin character, aerial mycelium, the size and coloration of the conidia etc. The growth facade was then noted by observing both the back and front views of the plates. Fungal slides were prepared with lactophenol cotton blue reagent and observed at $\times 40$ and $\times 100$ magnifications following standard protocols. ${ }^{14}$

\section{Small scale cultivation to obtain fungal extracts}

All the isolated fungal strains were cultured on PDA with approximately $500 \mathrm{~mL}$ of media. After the completion of 21 days incubation period at $28^{\circ} \mathrm{C}$, the culture media (PDA) were extracted with ethyl acetate to obtain the crude extracts. After each 05 days, media were filtrated through fresh cotton bed and finally with Whatman No.1 filter paper. The eight fungal extract were concentrated into solid residue by evaporation under rotary evaporator. ${ }^{15}$

\section{Screening the antimicrobial activity of endophytic fungal extracts}

The fungal extracts were subjected to screening for antimicrobial activities against four bacterial strains Staphylococcus aureus ATCC 25923, Escherichia coli ATCC 28739, Bacillus megaterium ATCC 28318 and Pseudomonas aeruginosa ATCC 27833, two fungal strains Aspergillus niger and $A$. flavus. Antimicrobial activity was determined by the established disc diffusion method ${ }^{16}$ and compared with the standard antibiotics Kanamycin and Ketoconazole for antibacterial and antifungal activities respectively at concentration of $30 \mu \mathrm{g} / \mathrm{disc}$. Solvent was used as negative control. The antimicrobial activity of the fungal extracts $(100 \mu \mathrm{g} /$ disc $)$ were determined by measuring the diameter of inhibition zone around each treated discand expressed in millimeter \pm standard deviation.

\section{Screening the antioxidant activity of endophytic fungal extracts}

A free radical scavenging assay was executed for the endophytic cultures as described by Braca et al. $2001^{17}$ using $2.0 \mu \mathrm{g} / \mathrm{mL}$ of $\mathrm{DPPH}$ in methanol. The free radical scavenging activities of the fungal extracts were measured at $517 \mathrm{~nm}$ and calculated according to the 
equation: percentage scavenging $(\%)=1-($ absorbance of sample at $517 \mathrm{~nm} /$ absorbance of control at 517 $\mathrm{nm}) \times 100 \%$. The percent radical scavenging activity was determined by a comparison with the positive control, ascorbic acid and trolox. The experiment was repeated three times.

\section{Screening the cytotoxic activity of endophytic fungal extracts}

For the evaluation of cytotoxic activity, brine shrimp lethality bioassay, designed by Meyer et al. $1982^{18}$ was performed. Dimethylsulphoxide (DMSO) was used as a negative control, whereas anticancer drug vincristine sulphate used as positive control for this investigation. Artemia salina (brine shrimp) was hatched and incubated in sea water for $24 \mathrm{hr}$. Samples of different concentrations from 400 to $0.781 \mu \mathrm{g} / \mathrm{mL}$ prepared by serial dilution in test tubes containing ten live nauplii in $5 \mathrm{ml}$ of sea water. The median lethal concentrations $\left(\mathrm{LC}_{50}\right)$ of the endophytes were determined after $24 \mathrm{hr}$ of observation by a plot of percentage of the shrimp mortality against the logarithm of the sample concentrations.

\section{Statistical analysis}

Mean $\mathrm{IC}_{50}$ values between groups were compared for antioxidant assay using independent student $t$-test for
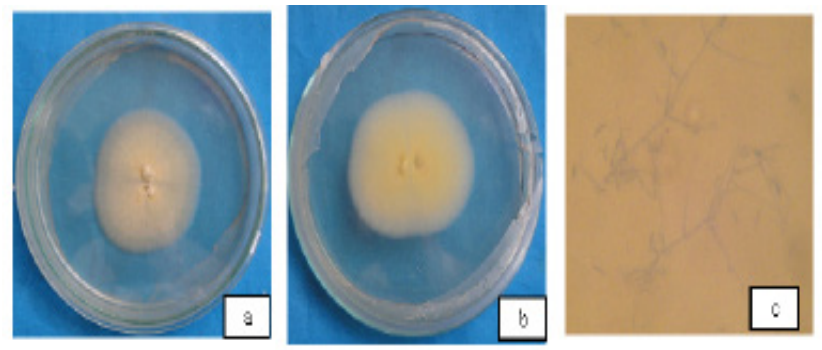

Figure 1: Macroscopic front (a) Macroscopic back (b) and Microscopic (c) view of leaves of Fusarium sp. (CDLE 1).
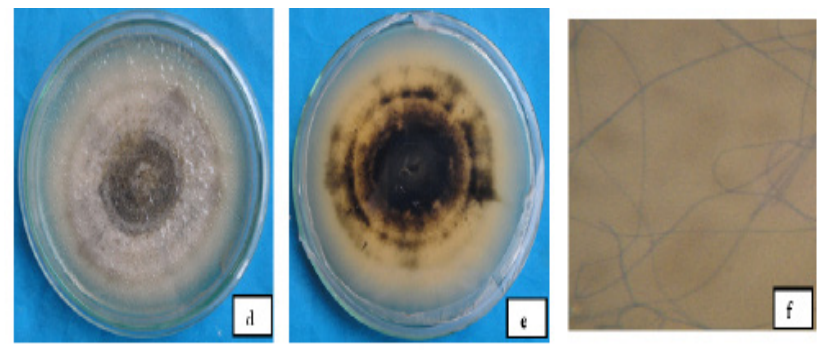

Figure 2: Macroscopic front (d) Macroscopic back (e) and Microscopic (f) view of leaves of unidentified sp. (CDLE 2). equality of variances. For the scrutiny of the antimicrobial results, standard deviation data was calculated.

\section{RESULTS AND DISCUSSION}

A total of eight endophytic fungi such as CDLE 1 (leaf endophyte, Figure 1), CDLE 2 (leaf endophyte, Figure 2), CDRE 1 (root endophyte, Figure 3), CDRE 2 (root endophyte, Figure 4), CDRE 3 (root endophyte, Figure 5), CDBE 1 (bark endophyte, Figure 6), CDBE 2 (bark endophyte, Figure 7) and CDBE 3 (bark endophyte, Figure 8) were isolated and purified on PDA medium from Commelina diffusa. Among them five (CDLE 1, CDRE 1, CDRE 2, CDRE 3, CDBE 1) endophytes were taxonmically identified as Fusarium sp., CDBE 3 was distinguished as Alternaria sp. on the basis of their macroscopic and microscopic morphological characters and remaining two fungi could not be identified from these macroscopic and microscopic morphological characters.

\section{Chemical screening}

Results of preliminary mycochemical screening are summarized in Table 1 . This investigation reveals the presence of various important chemical groups in different fungal extracts of this plant. These bioactive secondary metabolites produced by the isolated
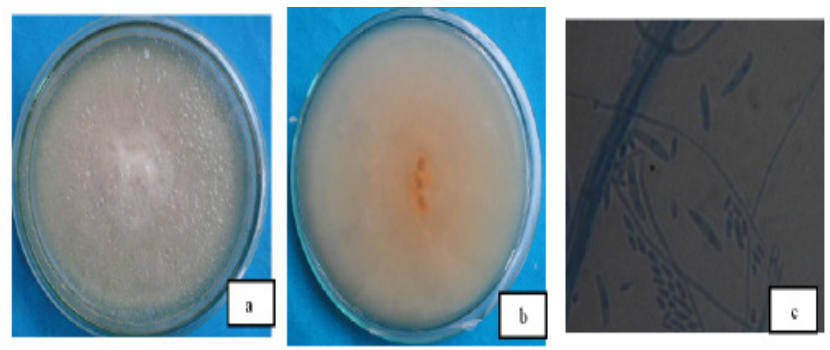

Figure 3: Macroscopic front (a) Macroscopic back (b) and Microscopic (c) view of root of Fusarium sp. (CDRE 1).
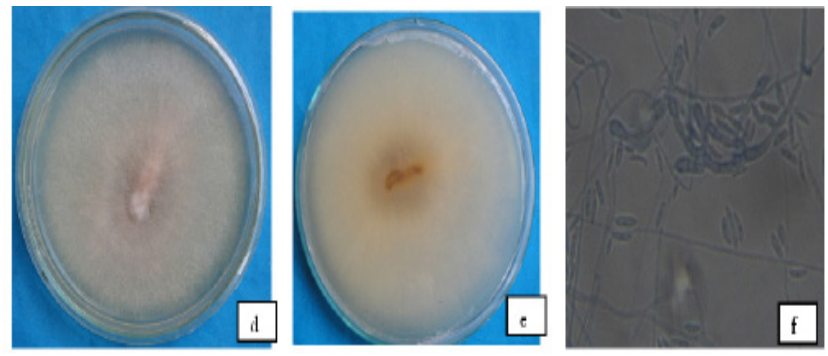

Figure 4: Macroscopic front (d) Macroscopic back (e) and Microscopic (f) view of root of Fusarium sp. (CDRE 2). 
endophytes are known to generate characteristics physiological action beneficial to plant (Figure 9).

\section{Macroscopic and microscopic identification}

\section{Strain CDLE 1, CDRE 1, CDRE 2, CDRE 3, CDBE 1}

After 3 days of culture in $\mathrm{PDA}$ at $28^{\circ} \mathrm{C}$, colony diameters of Fusarium sp. under light were found to be 3 to 4.4 $\mathrm{cm}$ (Figure 1, Figure 3-6). Aerial mycelia were abundant, densely floccose to fluffy and off white to pinkish in color and colony undersides on PDA were of pale orange and off white colored. Orange sporodochia were present in most isolates. No odor was detected. Microconidia were produced in false heads on monophialides or polyphialides, mostly nonseptate, oval, obovoid with a truncate base, elliptical in shape. Macroconidia were born in sporodochia, typically three-septate, fusiform, with slightly curved apical cell. Chlamydospores were smooth, intercalary or terminal and produced in single or in pairs. Phialides of the conidiophores were cylindrical, consisting of short monophialides up to $10 \mu \mathrm{m}$ long and $4.0 \mu \mathrm{m}$ wide, or longer and more slender monophialides up to $41 \mu \mathrm{m}$ long and $2.5 \mu \mathrm{m}$ wide. Depending on these morphological characters these species were identified as Fusarium sp.

\section{Strain CDBE 3}

Strain CDBE 3 showed hyaline mycelium that turned to grey-brownish, multicelled, septate and irregularly branched (Figure 8). In early growing stage, hyphae were thin $(2.84 \mu \mathrm{m}$ in diameter $)$, narrow, hyaline but
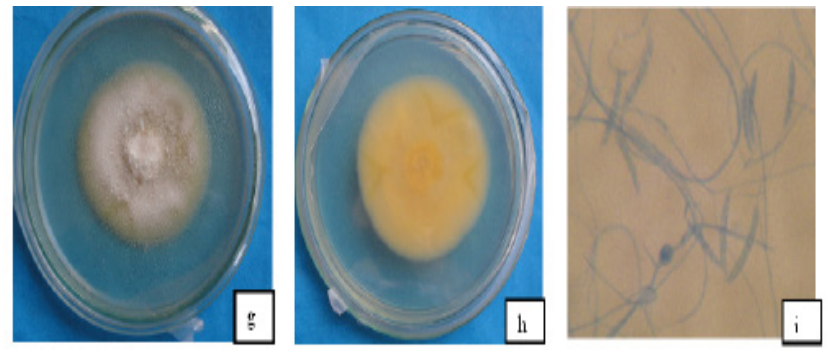

Figure 5: Macroscopic front (g) Macroscopic back (h) and Microscopic (i) view of root of Fusarium sp. (CDRE 3).
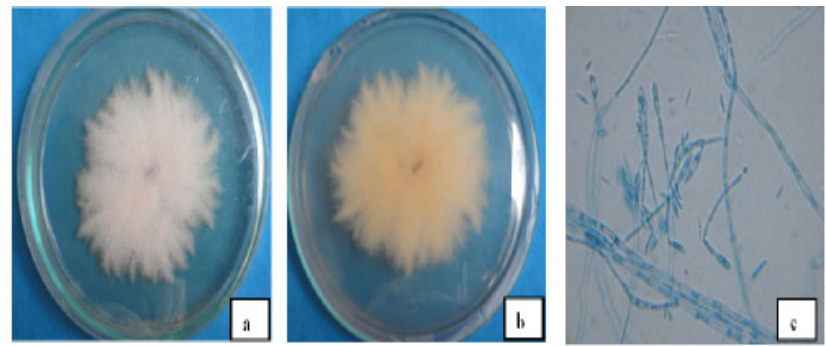

Figure 6: Macroscopic front (a) Macroscopic back (b) and Microscopic (c) view of bark of Fusarium sp. (CDBE 1). became slightly thick (4.42 $\mu \mathrm{m}$ in diameter) as they grew old. Conidiophores a rised singly or in clusters, pale olivaceous to olivaceous-brown, straight or curved, geniculate, slightly swollen at apex having terminal scars indicating the point of attachment of conidia. From these characteristics CDBE 3 was identified as Alternaria sp.
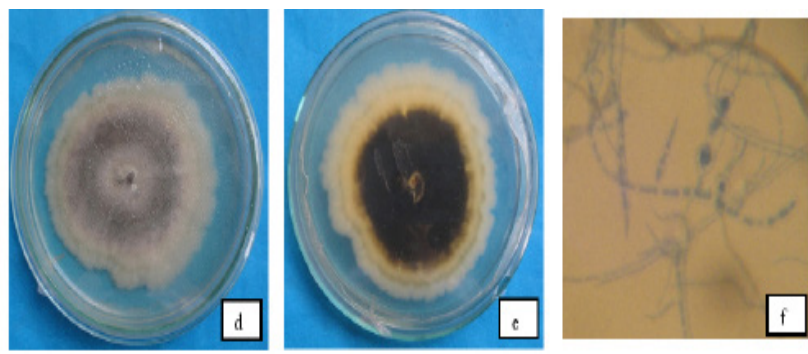

Figure 7: Macroscopic front (d) Macroscopic back (e) and Microscopic (f) view of bark of unidentified sp. (CDBE 2).
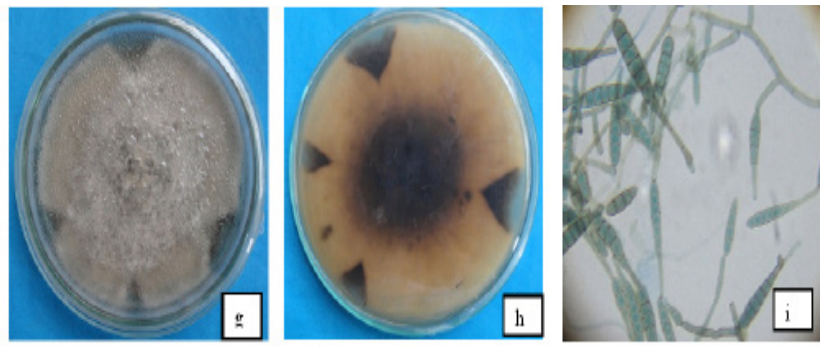

Figure 8: Macroscopic front (g) Macroscopic back (h) and Microscopic (i) view of bark of Alternaria sp. (CDBE 3).
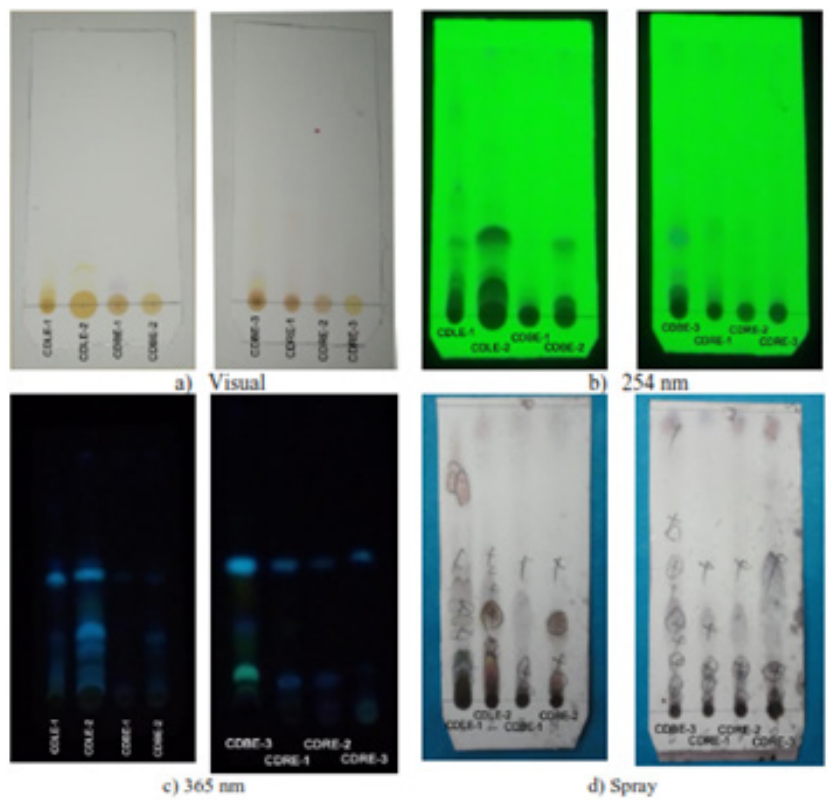

Figure 9: TLC screening of the fungal extracts (CDLE-1, CDLE-2, CDBE-1, CDBE-2, CDBE-3, CDRE-1, CDRE-2, CDRE-3) by visual observation (a), under UV at $254 \mathrm{~nm}$ (b), at $365 \mathrm{~nm}$ (c) and finally after spraying with spray reagent (d). 


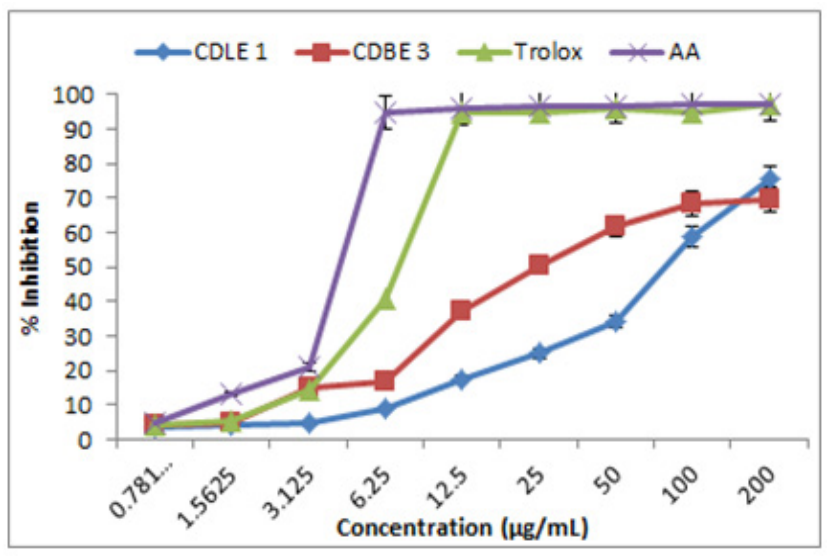

Figure 10: Free radical scavenging activity of different concentrations of endophytic fungi, Fusarium sp. (CDLE 1), Alternaria sp. (CDBE 3) and two standards.

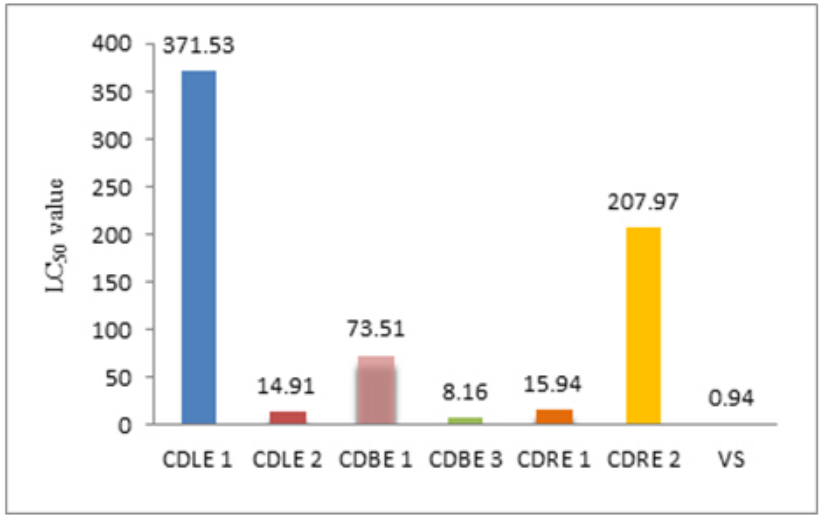

Figure 11: LC $_{50}$ values of the standard (VS) and different endophytic fungi of Commelina diffusa.

Table 1: Preliminary chemical screening of fungal ethyl acetate extracts.

\begin{tabular}{|c|c|c|c|c|c|}
\hline Fungal Extract & Visual color & UV light at $254 \mathrm{~nm}$ & $\begin{array}{c}\text { UV light at } 365 \\
\mathrm{~nm}\end{array}$ & After spray & Remarks \\
\hline \multirow{4}{*}{ CDLE 1} & Yellow & Dark & Orangish & Purple & $\begin{array}{l}\text { Anthraquinone/ } \\
\text { Flavonoid }\end{array}$ \\
\hline & Orange Red & Dark & Blue & Purple & Anthocyanin \\
\hline & \multirow{2}{*}{ - } & Dark & Blue & Purple & Coumarin \\
\hline & & Dark & - & Purple & Terpenoid \\
\hline \multirow{3}{*}{ CDLE 2} & Yellow & Dark & Blue & - & Flavonoid \\
\hline & \multirow{2}{*}{-} & Dark & Blue & Green & Coumarin/ Flavonoid \\
\hline & & Dark & Blue & Red/Purple & Coumarin \\
\hline \multirow{2}{*}{ CDBE 1} & Light purple & Dark & - & Purple & Anthocyanin \\
\hline & - & Dark & Blue & - & Coumarin \\
\hline \multirow{3}{*}{ CDBE 2} & - & Dark & Blue & - & Coumarin \\
\hline & - & Dark & - & $\begin{array}{c}\text { Red/ } \\
\text { Brick red }\end{array}$ & Terpenoids \\
\hline & - & Dark & Blue & Purple & Flavonoid/ Coumarin \\
\hline \multirow{3}{*}{ CDBE 3} & Yellow & Dark & Orange & Purple & $\begin{array}{c}\text { Flavonoid/ } \\
\text { Anthraquinone }\end{array}$ \\
\hline & & Dark & Greenish & - & Coumarins \\
\hline & Orange red & Dark & Blue & Purple & $\begin{array}{c}\text { Flavonoid/ } \\
\text { Anthraquinone }\end{array}$ \\
\hline \multirow{4}{*}{ CDRE 1} & Purple & Dark & - & Purple & Anthocyanin \\
\hline & Orange red & Green & Red & Purple & Flavonoid \\
\hline & \multirow[b]{2}{*}{-} & Black/Blue & Blue & & Coumarin \\
\hline & & Dark & - & $\begin{array}{l}\text { Purple/ } \\
\text { Brown }\end{array}$ & Terpenoids \\
\hline \multirow{3}{*}{ CDRE 2} & Purple & Dark & - & Purple & Terpenoids/ Anthraquinone \\
\hline & Orange red & Green & Red & Purple & Flavonoid \\
\hline & - & Blue & Blue & - & Coumarin \\
\hline CDRE 3 & - & Dark & Blue & Red/Brick red & Flavonoid/ Coumarins \\
\hline
\end{tabular}


Table 2: Antimicrobial activity of endophytic fungal strains isolated from Commelina diffusa.

\begin{tabular}{|c|c|c|c|c|c|c|c|}
\hline \multirow{4}{*}{\multicolumn{2}{|c|}{ Sample }} & \multicolumn{6}{|c|}{ Diameter of Zone of Inhibition (mm) } \\
\hline & & \multicolumn{3}{|c|}{ Bacteria Strain (Mean $\pm S D$ ) } & & \multicolumn{2}{|c|}{ Fungal Strain } \\
\hline & & \multicolumn{2}{|c|}{ Gram Negative } & \multicolumn{2}{|c|}{ Gram Positive } & \multirow[b]{2}{*}{ A. niger } & \multirow[b]{2}{*}{ A. flavus } \\
\hline & & E. coli & $P$. aeruginosa & B. megaterium & S. aureus & & \\
\hline \multicolumn{2}{|c|}{ CDLE 1} & $14.2 \pm 0.763$ & $11.8 \pm 0.763$ & $9.6 \pm 0.360$ & $11.6 \pm 0.513$ & - & - \\
\hline \multicolumn{2}{|c|}{ CDLE 2} & $11.5 \pm 0.5$ & $9.6 \pm 0.513$ & - & $9.6 \pm 0.793$ & - & - \\
\hline \multicolumn{2}{|c|}{ CDBE 1} & - & - & - & - & - & - \\
\hline \multicolumn{2}{|c|}{ CDBE 2} & $10.4 \pm 0.351$ & $10.5 \pm 0.5$ & - & $10 \pm 0.5$ & $27.5 \pm 0.5$ & - \\
\hline \multicolumn{2}{|c|}{ CDBE 3} & $9.2 \pm 0.2$ & $9.8 \pm 0.680$ & - & $8.7 \pm 0.707$ & - & - \\
\hline \multicolumn{2}{|c|}{ CDRE 1} & $11.8 \pm 1.755$ & $10.4 \pm 0.513$ & $9.5 \pm 0.5$ & $10.7 \pm 1.101$ & $29.7 \pm 0.642$ & - \\
\hline \multicolumn{2}{|c|}{ CDRE 2} & $21.9 \pm 1.101$ & $9.5 \pm 0.5$ & $10.6 \pm 0.655$ & $9.3 \pm 1.040$ & $30.3 \pm 0.351$ & $20.4 \pm 0.360$ \\
\hline \multicolumn{2}{|c|}{ CDRE 3} & $9.9 \pm 0.360$ & - & - & $11.4 \pm 1.216$ & - & - \\
\hline \multirow{2}{*}{$\begin{array}{c}\text { Positive } \\
\text { control } \\
(30 \mu \mathrm{g} / \mathrm{disc})\end{array}$} & $\mathrm{KM}$ & $33 \pm 1.0$ & $34.5 \pm 0.5$ & $49.6 \pm 0.513$ & $36.5 \pm 0.5$ & - & - \\
\hline & $\mathrm{KC}$ & - & - & - & - & $39.8 \pm 0.763$ & $42.5 \pm 0.5$ \\
\hline
\end{tabular}

(-) No Activity

CDLE 2 and CDBE 2 were not identified as their spore was absent (Figure 2, Figure 7). But their bioactivity was checked for potential response.

\section{Antimicrobial activity screening}

There were eight endophytic fungi isolated and screened for antimicrobial activity against the tested pathogenic micro-organism (Table 2). Three fungi (CDBE 2, CDRE 1 , and CDRE 2) showed potential activity against $A$. niger in comparison with ketoconazole $(30 \mu \mathrm{g} / \mathrm{disc})$. Results showed that, two of the eight fungi (CDLE 1 and CDRE 2) showed moderate inhibitory effect towards E. coli with inhibition zone of more than $12 \mathrm{~mm}$, while others fungi produced inhibition less than $10 \mathrm{~mm}$ on $P$. aeruginosa, B. megaterium, $S$. aureus.

\section{Antioxidant activity screening}

The endophytic DPPH radical scavenging potential was assessed in contrast to the positive control (ascorbic acid). To explore the antioxidant potential of the eight isolated endophytes, two were analyzed for their capacity to scavenge oxidative radicals. The results demonstrated that CDLE 1 and CDBE 3 had higher radical scavenging abilities with $\mathrm{IC}_{50}$ value of $105.48 \mu \mathrm{g} / \mathrm{mL}$ and $32.36 \mu \mathrm{g} /$ $\mathrm{mL}$ compared to the ascorbic acid $(4.37 \mu \mathrm{g} / \mathrm{mL})$ and trolox $(4.79 \mu \mathrm{g} / \mathrm{mL}$ ) respectively (Figure 10). CDLE-1 showed significant variation in mean $\mathrm{IC}_{50}$ value as compared to standards $(p<0.01)$ whereas CDBE 3 did not exhibited significant variation in mean $\mathrm{IC}_{50}$ value from the standards $(p>0.05)$. So CDBE 3 has the capacity to release secondary metabolites which may have high antioxidant activity.

\section{Cytotoxic activity screening}

In cytotoxic activity evaluation, the standard vincristine sulphate (VS) that was used as positive control for which $\mathrm{LC}_{50}$ was found to be $0.94 \mu \mathrm{g} / \mathrm{mL}$. The $\mathrm{LC}_{50}$ values of CDLE 1, CDLE 2, CDBE 1, CDBE 3, CDRE 1 and CDRE 2 were found to be $371.53 \mu \mathrm{g} / \mathrm{mL}, 14.91 \mu \mathrm{g} /$ $\mathrm{mL}, 73.51 \mu \mathrm{g} / \mathrm{mL}, 8.16 \mu \mathrm{g} / \mathrm{mL}, 15.94 \mu \mathrm{g} / \mathrm{mL}$ and $207.97 \mu \mathrm{g} / \mathrm{mL}$ respectively (Figure 11). Comparing these values with the value obtained from standard, it was observed that these endophyte CDBE 3 (Alternaria sp.) and CDRE 1 (Fusarium sp.) were quite lethal for the brine shrimp nauplii.

\section{CONCLUSION}

Successive sterilization, isolation and purification yielded a total of eight endophytic fungi. From the biological investigations, it is proved that, the endophytic fungi of $C$. diffusa exhibited moderate antimicrobial activity and strong antioxidant, cytotoxic activities. However, further, studies are required to isolate more bioactive compounds responsible for the activities of these endophytic fungi of Commelina diffusa. 


\section{ACKNOWLEDGEMENT}

The authors are thankful to Bangladesh Council of Scientific and Industrial Research (BCSIR) for providing necessary facilities to carry out the study.

\section{CONFLICT OF INTEREST}

The authors declare that there is no conflict of interests regarding the publication of this paper.

\section{ABBREVIATIONS}

CNS: Central nervous system; PDA: potato dextrose agar; TLC: Thin layer chromatography; DPPH: 2,2-diphenyl-1-picrylhydrazyl; DMSO: Dimethylsulphoxide; VS: vincristine sulphate.

\section{REFERENCES}

1. Wilson D. Endophyte: The evolution of a term and clarification of its use and definition. Oikos. 1995;73(2):274-6.

2. Joseph B, Priya RM. Bioactive compounds from endophytes and their potential in pharmaceutical effect: A review. Am J Biochem Mol Biol. 2011;1(3): 291-309.

3. Nasrin M, Afroz F, Sharmin S, Rana MS, Sohrab MH. Cytotoxic, antimicrobial and antioxidant properties of Commelina diffusa Burm. F. Pharmacology and Pharmacy. 2019;10(02):82-93.

4. Mensah AY, Mireku EA, Damoah AO, Amponsah IK. Anti-inflammatory and antioxidant activities of Commelina diffusa (Commelinaceae). World J Pharm Sci. 2014;2(10):1159-65.
5. Oulowagbenga S. Effect of drying methods on the anti-microbial properties of Cassia alata, Commelina diffusa and Borreria verticillata extracts. Egypt Exp Biol. 2017;13(2):181-6.

6. Sule OJ, Arhoghro EM, Erigbali P. Nephron-protective and hepato-protective property of Commelina diffusa leaf extract in doxorubicin-induced albino rats. World J Pharm Sci. 2017;6(10):51-62.

7. Sultana T, Mannan MA, Ahmed T. Evaluation of central nervous system (CNS) depressant activity of methanolic extract of Commelina diffusa Burm. in mice. Clin Phytoscience. 2018;4(1):5.

8. Petrini O. Taxonomy of endophytic fungi of aerial plant tissues. Microbiology of the Phyllosphere. Cambridge University Press. 1986;175-87.

9. Wagner H, Bladt S. Plant drug analysis, a thin layer chromatography Atlas. Second edition, Springer. 1996.

10. Pascual ME, Carretero ME, Slowing KV, Villar A. Simplified Screening by TLC of Plant Drugs. Pharm Biol. 2002;40(2):139-43.

11. Harborne JB. Phytochemical Methods. A guide to modern techniques of plant analysis. Norfolk: Fakenham Press Limited. 1973.

12. Devi NN, Prabakaran JJ. Bioactive metabolites from an endophytic fungus Penicillium sp. Isolated from Centella asiatica. Curr Res Environ and Appl. 2014;4(1):34-43.

13. Barnett HL, Hunter BB. Illustrated genera of imperfect fungi. St. Paul. Minnesota: APS Press; 1998.

14. Sadananda TS, Govindappa M, Ramachandra YL. In vitro antioxidant activity of lectin from different endophytic fungi of Viscum album L. Br J Pharm Res. 2014;4(5):626-43.

15. Alzoreky NS, Nakahara K. Antibacterial activity of extracts from some edible plants commonly consumed in Asia. Int J Food Microbiol. 2003;80(3):223-30.

16. Bauer AW, Kirby M, Sherris JC, Turck M. Antibiotic susceptibility testing by a standardized single disc method. Am J Clin Pathol. 1966;45(4):493-6.

17. Braca A, Tommasi ND, Bari LD, Pizza C, Politi M, Morelli I. Antioxidant Principles from Bauhinia terapotensis. J Nat Prod. 2001;64(7):892-5.

18. Meyer BN, Ferrigni NR, Putnam JE, Jacobsen LB, Nichols DE, McLaughlin JL. Brine Shrimp: A convenient general bioassay for active plant constituents. Planta Med. 1982;45(1):31-4.

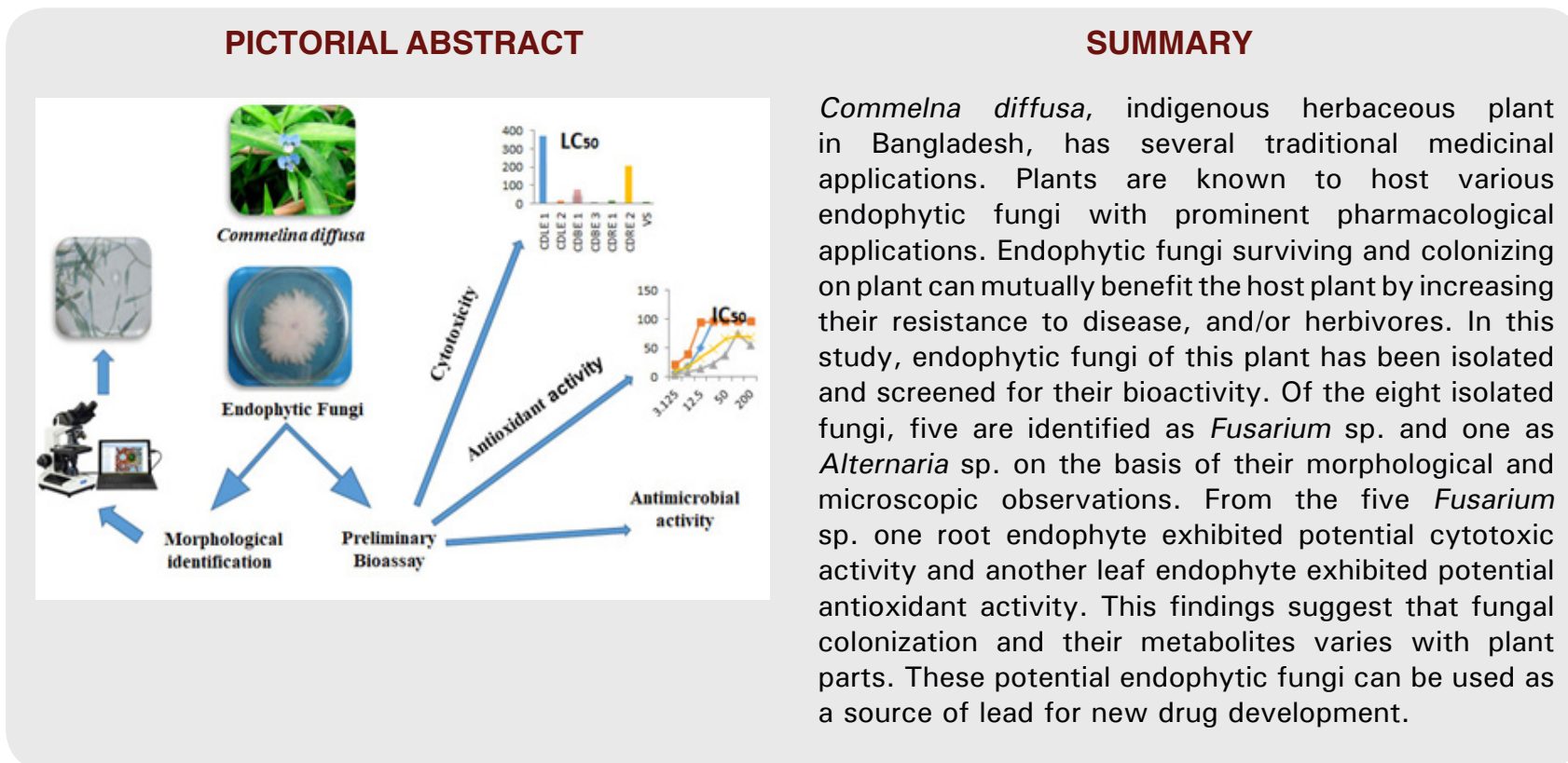




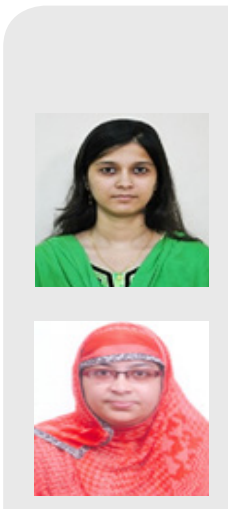

About Authors

Mahmuda Nasrin, PhD Scholar in Department of Pharmacy, Jahangirnagar University, Savar, and Doctoral Fellow, Pharmaceutical Sciences Research Division, BCSIR Laboratories, Dhaka. She is carrying out the PhD research work under the guidance of Prof. Dr. Md. Sohel Rana and Dr. Md. Hossain Sohrab. She has published 10 international and national publications.

Dr. Farhana Afroz, Senior Scientific Officer, Pharmaceutical Sciences Research Division, BCSIR Laboratories, Dhaka. With PhD in medical biotechnology Dr. Farhana has 15 yrs of research experience. She has published more than 18 international and national publications.

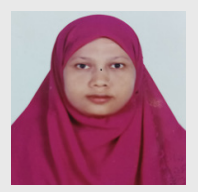

Mst. Nadira Begum, Senior Scientific Officer, Biological Research Division, BCSIR Laboratories Dhaka. She has 15 yrs of research experience and published 20 international and national publications.

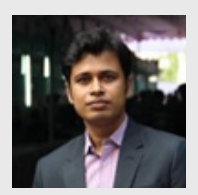

Satyajit Roy Rony, Senior Scientific Officer, Pharmaceutical Sciences Research Division, BCSIR Laboratories, Dhaka. He has 10 yrs of research experience and published 23 international and national publications.

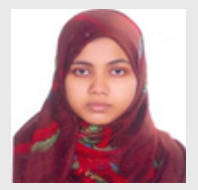

Suriya Sharmin, Senior Scientific Officer, Pharmaceutical Sciences Research Division, BCSIR Laboratories, Dhaka. She has 8 yrs of research experience with 12 international and national publications.

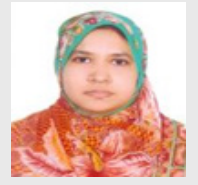

Fatema Moni, Senior Scientific Officer, Pharmaceutical Sciences Research Division, BCSIR Laboratories, Dhaka. She has 5 yrs of research experience with 06 publications.

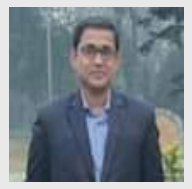

Dr. Md. Sohel Rana, Professor, Jahangirnagar University, Savar, Dhaka. He is having 29 yrs of teaching and research experience. He has published 05 books and more than 210 international and national publications.

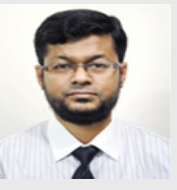

Dr. Md. Hossain Sohrab, Chief Scientific Officer, Scientist-in-Charge, Pharmaceutical Sciences Research Division, BCSIR Laboratories, Dhaka. He is involved with research in the area of medicinal and natural product chemistry for the last 23 years. Presently he is working as a Project Director of the "Establishment of Institute of Bioequivalence Studies and Pharmaceutical Sciences" project, BCSIR, Dhaka. He has published more than 90 international and national publications and has 01 international patent.
\end{abstract}

Cite this article: Nasrin M, Afroz F, Begum N, Rony SR, Sharmin S, Moni F, et al. Isolation and Bioactivity Screening of Endophytic Fungi from Commelina diffusa. Indian J of Pharmaceutical Education and Research. $2021 ; 55(3): 829-36$. 